\title{
Overtone Mobility Spectrometry: Part 4. OMS-OMS Analyses of Complex Mixtures
}

\author{
Ruwan T. Kurulugama, ${ }^{1,2}$ Fabiane M. Nachtigall, ${ }^{1,3}$ Stephen J. Valentine, ${ }^{1}$ \\ David E. Clemmer ${ }^{1}$ \\ ${ }^{1}$ Department of Chemistry, Indiana University, Bloomington, IN 47405, USA \\ ${ }^{2}$ Pacific Northwest National Laboratory, Richland, WA 99352, USA \\ ${ }^{3}$ Max-Planck Inst. für Kohlenforschung, Mülheim/Ruhr, Germany
}

\begin{abstract}
A new, two-dimensional overtone mobility spectrometry (OMS-OMS) instrument is described for the analysis of complex peptide mixtures. OMS separations are based on the differences in mobilities of ions in the gas phase. The method utilizes multiple drift regions with modulated drift fields such that only ions with appropriate mobilities are transmitted to the detector. Here we describe a hybrid OMS-OMS combination that utilizes two independently operated OMS regions that are separated by an ion activation region. Mobility-selected ions from the first OMS region are exposed to energizing collisions and may undergo structural transitions before entering the second OMS region. This method generates additional peak capacity and allows for higher selectivity compared with the one-dimensional OMS method. We demonstrate the approach using a three-protein tryptic digest spiked with the peptide Substance $P$. The $[M+3 H]^{3+}$ ion from Substance $\mathrm{P}$ can be completely isolated from other components in this complex mixture prior to introduction into the mass spectrometer.
\end{abstract}

Key words: Ion mobility spectrometry, Overtone mobility spectrometry, Mass spectrometry, Complex mixture analysis

\section{Introduction}

$\mathrm{R}$ ecently we have described a new separation technique called overtone mobility spectrometry (OMS) that separates ions based on differences in their mobilities in the gas phase [1-5]. The mobility of an ion through a defined buffer gas is a fundamental property of the ion that is related to its shape, mass and charge and is the basis for the widely used technique known as ion mobility spectrometry (IMS) [6-20]. However, unlike conventional IMS that utilizes an electrostatic gate to introduce a packet of ions into a drift region, OMS uses multiple segmented drift regions with modulated drift fields to produce conditions that allow only ions with appropriate mobilities to pass through the instrument [1-5]. Therefore, the instrument acts as a mobility filter and can provide a continuous beam of

Correspondence to: David E. Clemmer; e-mail: clemmer@indiana.edu mobility-selected ions. Upon scanning the applied drift field frequency, a peak corresponding to the expected resonance time of the ions in one drift segment is observed, as well as a series of peaks at higher frequencies that correspond to overtones of the resonant frequency [1-3]. The measured resolving power is observed to increase with increasing overtone numbers, such that it is possible to resolve structures at higher overtones that are not resolved in the fundamental frequency region. The technique is highly complementary to mass spectrometry (MS) as a means of producing structural information because it provides information about the ion's collision cross section. Because the approach is a filter that can be used to produce a continuous stream of ions, analogies can be drawn with quadrupole mass filters.

In the present work, we describe an OMS-OMS technique. A beam of mobility-selected ions is transmitted through an initial OMS region. These ions are exposed to energizing collisions with the buffer gas to induce structural transitions 
and the new structures are filtered again in a second OMS region. This allows individual components of a complex mixture to be isolated prior to MS analysis. Using this twodimensional approach it is possible to create what is effectively a continuous beam of a narrow distribution of mobility selected ions from a complex mixture.

Two-dimensional IMS-IMS techniques were introduced several years ago [21-23]. In IMS-IMS a pulse of ions is introduced into the first drift tube for mobility separation. At the end of the first drift tube ions with similar mobilities are selected and subjected to energizing collisions in order to introduce structural changes. The new structures are then separated in the second drift tube. This IMS-IMS approach has resulted in a total peak capacity prior to MS analysis in excess of 1000 [23]. Using a validated theoretical expression for the resolving power of OMS separations $[2,5]$, it is estimated that the OMS-OMS peak capacity exceeds 500 . The high resolution capabilities are demonstrated by the complete isolation of a single peptide within a sample mixture generated by tryptic digestion of three separate proteins. Finally, the OMS-OMS experiments where precursor ions are isolated and collisionally activated followed by isolation of product ions are analogous to selected reaction monitoring (SRM) [24] experiments performed on triple quadrupole instruments.

\section{Experimental}

\section{General}

Theoretical aspects of IMS separations as well as instrumentation and methods have been described in detail previously $[6,7,9,10,15,18-20,25-42]$. The instrument used in this study is a modified version of existing IMS-MS instruments described previously [21, 43, 44]. The electrospray ionization (ESI) source and all the components that come after the OMS regions are unchanged. The OMS device is obtained simply by reconfiguring our existing linear IMS instrument. Thorough descriptions of considerations associated with OMS operation are provided elsewhere [1-5]. Only a brief discussion relevant to OMS-OMS instrumentation is given here.

Figure 1A shows a schematic diagram of the OMS-OMS instrument used in these studies. Ions are produced using a home-built ESI source and are continuously focused through an hour-glass ion funnel (F1) [38] interface into a short $(7.5 \mathrm{~cm})$ linear drift tube that is connected to the segmented drift region. The linear drift tube allows introduction of a continuous ion beam into the segmented drift tube region. The first segmented region (OMS1) is $58.4 \mathrm{~cm}$ long and consists of 10 segments $(5.84 \mathrm{~cm}$ long each). OMS1 is operated using a four-phase wave driver [2] and the drift field is maintained at $10 \mathrm{~V} \cdot \mathrm{cm}^{-1}$. The four-phase wave driver providing the voltage setting for the drift tube is built inhouse and the input pulse to the wave driver is provided by a four-channel digital pulse generator (model DG535; Stanford
Research Systems, Inc., Sunnyvale, CA, USA). This wave driver generates four drift field application settings that are sequentially switched at a given frequency to move the ions through the drift tube $[1,3]$. Ions with an appropriate mobility enter the second segmented drift tube through an ion funnel (F2) $[45,46]$. The second OMS region is comprised of 11 segments and is $64.2 \mathrm{~cm}$ long. The OMS2 region is operated using a three-phase wave driver. The electric field is maintained at $9 \mathrm{~V} \cdot \mathrm{cm}^{-1}$. The three- and four-phase wave drivers are connected to frequency generators built in-house that can be fixed at a specific frequency to transmit a specific ion, or swept over a range of frequencies to produce an OMS spectrum. The choice of wave driver used to drive ions through the OMS2 is arbitrary; a four-phase system has been used because of its ready availability. That said, any combination of different phases can be used in a twodimensional OMS experiment. It is interesting that the pattern of overtone peaks is phase dependent as described previously [2]. Therefore, to some extent, the frequency range can be tuned by choice of wave driver phase. Ions that exit the OMS2 region are focused into the source region of a reflectron geometry time-of-flight (TOF) mass spectrometer for mass analysis as described previously.

\section{Nomenclature Associated with OMS-MS and OMS-OMS-MS Data Sets}

We have described a nomenclature for IMS-IMS-MS data sets [21] that is analogous to one used for MS-MS data [47]. We extend it here for OMS-OMS-MS datasets. First, the position of peaks in these data can be described by values of field application frequency (flight time) [or $\left.f\left(t_{\mathrm{F}}\right)\right]$ similar to the IMSMS nomenclature introduced previously [33]. Flight times in the mass spectrometer are usually converted to mass-to-charge $(\mathrm{m} / \mathrm{z})$ values by using a standard multipoint calibration. In addition to the primary peak (designated as the fundamental frequency or $f_{f}$ ) in the frequency spectrum, there are other peaks that appear at higher frequencies (overtone peaks). It is important to designate the overtone frequency (or fundamental level) as a multiple of the fundamental frequency when reporting a given peak. With that information, the final nomenclature can be given as follows; harmonic number (or overtone number+1)[2] multiplied by $f_{f}$. For example the peak position for the Substance $\mathrm{P}[\mathrm{M}+3 \mathrm{H}]^{3+}$ ion at the fundamental frequency range and another peak for the same ion at the fifth harmonic range, would be given as $f_{f}(\mathrm{~m} / \mathrm{z}), 2675(450.20)$ and $5 f_{f}(\mathrm{~m} / \mathrm{z}), 13224(450.20)$, respectively.

Figure 1B shows the basic symbolism and nomenclature used for describing the operational modes for this method. For OMS data, a closed triangle ( $\mathbf{\Delta})$ denotes a fixed (or selected) frequency while an open triangle $(\triangle)$ denotes a variable or scanned frequency. For TOF MS experiments, an open circle $(\bigcirc)$, represents a variable mass. Selected and variable transitions (frequency or mass) are denoted by arrows. For hybrid instruments, these symbols can be 
(A)

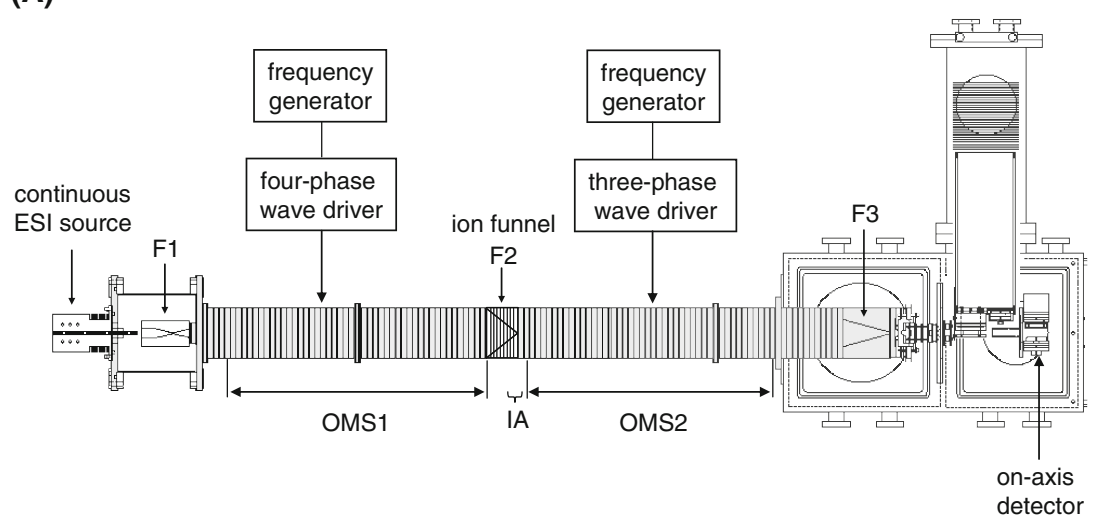

(B)

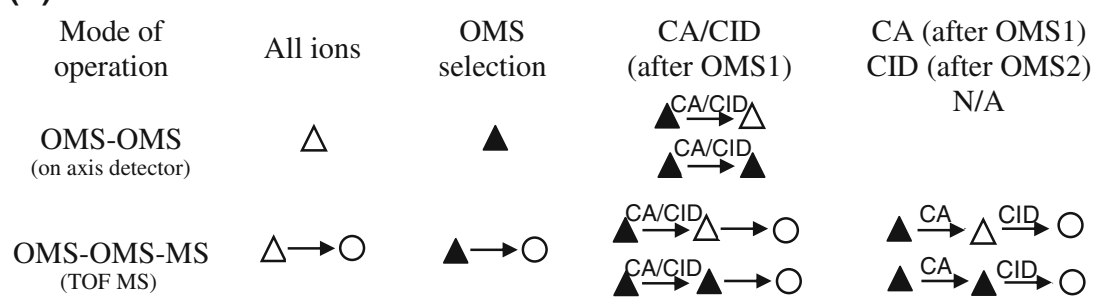

Glossary of symbols

A fixed field application frequency

$\triangle$ scanned or variable field application frequency

variable mass

$\longrightarrow$ fixed or variable transition

Figure 1. Schematic diagram of the two-dimensional OMS instrument used in this study (A) and the symbolism and the nomenclature used to describe the different modes of operation for this instrument, including a glossary of symbols (B). Here, an ESI source introduces electrosprayed ions into the first OMS region through an hour-glass ion funnel (F1). The OMS1 region is operated using a four-phase wave driver and the second OMS region is operated using a three-phase wave driver. A reflectron geometry timeof-flight mass spectrometer (TOFMS) is used for mass analysis. The mobility selected ions from the OMS1 region are introduced into the OMS2 region through a conventional ion funnel (F2) with an ion activation (IA) region at the end of the funnel. OMS-OMS and OMS-OMS-MS data can be recorded using the on-axis detector and the TOF MS analyzer, respectively. Ion activation is denoted as collisional activation (CA) or collision-induced dissociation (CID)

combined to describe the multidimensional measurements of OMS-MS. Examples for the use of this nomenclature are provided in the Results and discussion section.

\section{Sample Preparation}

Horse myoglobin ( $\geq 95 \%$ purity), human hemoglobin $(\geq 90 \%$ purity), horse cytochrome $c(\geq 95 \%$ purity), and Substance P ( $\geq 95 \%$ purity) were purchased from Sigma (Sigma Chemical, St. Louis, MO, USA) and used without further purification. Enzymatic digestion is carried out for each protein separately and tryptic peptide mixtures are obtained as follows. Myoglobin, hemoglobin, and cytochrome $c$ were initially dissolved in $6 \mathrm{M}$ urea buffer and the sample is diluted to $2 \mathrm{M}$ urea using $0.2 \mathrm{M}$ Tris buffer $\left(\mathrm{pH}=8.0,10 \mathrm{mM} \mathrm{CaCl}_{2}\right)$ before trypsin digestion. Tryptic peptides are generated by adding TPCK-treated trypsin $(2 \%$ enzyme by mass to that of the protein) and incubating the solution at $37{ }^{\circ} \mathrm{C}$ for $24 \mathrm{~h}$. Finally, the mixture of peptides is desalted using Oasis hydrophilic-lipophilic balanced (HLB) cartridges (Waters Inc., Milford, MA, USA) and dried on a centrifugal concentrator (Labconco Corporation, Kansas City, MO, USA). Dried peptides $\left(5.0 \times 10^{-2} \mathrm{~g}\right)$ are resuspended in $1.0 \mathrm{~mL}$ of water: acetonitrile:formic acid solution (49\%:49\%:2\% by volume). Substance $\mathrm{P}$ is added to the sample $\left(4 \times 10^{-6} \mathrm{M}\right)$ and the mixture is infused through a pulled-tip capillary using a syringe pump (KD Scientific Inc., Holliston, MA, USA) at a flow rate of $300 \mathrm{~nL} \cdot \mathrm{min}^{-}$ ${ }^{1}$. The tip is biased at $\sim+2000 \mathrm{~V}$ relative to the entrance aperture of the instrument to produce electrosprayed droplets.

\section{Ion Funnel and Ion Activation Region}

The F2 ion funnel is comprised of 22 stainless steel electrodes $(12.7 \mathrm{~cm}$ o.d.) with aperture diameters that decreased linearly from 7.00 to $0.56 \mathrm{~cm}$. The first funnel lens as well as the 18th and 19th lenses contain 90\% transmittance Ni mesh grids (Buckbee-Mears, St. Paul, MN, 
USA). The rf field is applied between lenses 2 to 17 . The 17 th lens contains the smallest aperture $(0.56 \mathrm{~cm})$. The region between lenses 18 and 19 is used as the ion activation region. The funnel lenses are separated by $0.18 \mathrm{~cm}$ thick Teflon spacers and the total length of the funnel is $5.74 \mathrm{~cm}$. The funnel is operated using rf fields of $50-70 \mathrm{~V}_{p-p}$ at $450 \mathrm{kHz}$ and a $10 \mathrm{~V} \cdot \mathrm{cm}^{-1} \mathrm{DC}$ field. The ions entering the funnel can be either allowed to pass through unaffected or subjected to energizing collisions at the exit of the funnel to induce structural changes. The activation region is operated at approximately $17 \mathrm{~V} \cdot \mathrm{cm}^{-1}$ to pass the precursor ions while the activation field is increased $\left(>500 \mathrm{~V} \cdot \mathrm{cm}^{-1}\right)$ to induce structural changes. For the present experiments the field application frequency for the OMS2 is scanned from $\sim 500 \mathrm{~Hz}$ to $\sim 36000 \mathrm{~Hz}$ in $100 \mathrm{~Hz}$ steps to obtain an OMS spectrum. However, the field application frequency for the OMS2 can also be held at specific frequencies to study selected ions.

The fundamental and overtone frequencies for any ion of interest with a known mobility can be calculated from $f_{f}=K E / d$. Here, $K$ is the mobility of the ion, $E$ is the electric field, and $d$ is the length of one drift segment $(5.84 \mathrm{~cm})[1,2]$. The drift tube is filled with He buffer gas at 2.25 Torr pressure and the temperature was maintained at $\sim 298 \mathrm{~K}$.

\section{Results and Discussion}

\section{OMS Analysis of a Three-Protein Tryptic Peptide Mixture that is Doped with Substance P}

Figure $2 \mathrm{C}$ shows the nested two-dimensional frequency $(\mathrm{m} / \mathrm{z})$ plot for the three-protein tryptic digest doped with Substance P. Here, both OMS1 and OMS2 regions and the F2 funnel are operated as one unit $(\Delta \rightarrow 0)$. This analysis is carried out by operating the instrument using a four-phase wave driver. Therefore, peaks at the $f_{f}, 5 f_{f}$, and $9 f_{f}$ frequency ranges and

Figure 2. Panel (C) shows a nested two-dimensional frequency $(\mathrm{m} / \mathrm{z})$ plot obtained upon electrospraying a threeprotein (hemoglobin, myoglobin and cytochrome $c$ ) tryptic digest with doped Substance $\mathrm{P}$ peptide at a concentration ratio of $10: 1$, respectively. Here, the instrument is operated using a four-phase wave driver. For this analysis, the OMS1, F2, and OMS2 regions are operated as a single unit. The frequency step increments between 1000 and $5000 \mathrm{~Hz}$ and 5000 and $35,000 \mathrm{~Hz}$ are $50 \mathrm{~Hz}$ and $100 \mathrm{~Hz}$, respectively. The OMS spectra (B) and the mass spectra (A) are obtained for the same sample. The bottom OMS spectrum, bottom trace in (B) is obtained by summing the signal at all $\mathrm{m} / \mathrm{z}$ values, and the top OMS spectrum given in (B) corresponds to the $[\mathrm{M}+$ $3 \mathrm{H}]^{3+}$ ion from Substance $\mathrm{P}$ (see text for details). The bottom mass spectrum (A) is obtained by integrating the signal across the whole frequency range. The mass spectra labeled $f_{f}, 5 f_{f}$, and $9 f_{f}$ in (A) are obtained by taking slices through the centers of the $f_{f}, 5 f_{f}$, and $9 f_{f}$ peaks for the $[\mathrm{M}+3 \mathrm{H}]^{3+}$ ion from Substance $P$, respectively smaller features in the $3 f_{f}$ range are expected $[1,2,5]$. For this experiment the field application frequency has been scanned from $1000 \mathrm{~Hz}$ to $35000 \mathrm{~Hz}$. The frequency step increments between 1000 and $5000 \mathrm{~Hz}$ and 5000 and $35000 \mathrm{~Hz}$ are 50 and $100 \mathrm{~Hz}$, respectively. The OMS distributions presented here are obtained from 2D OMS-MS
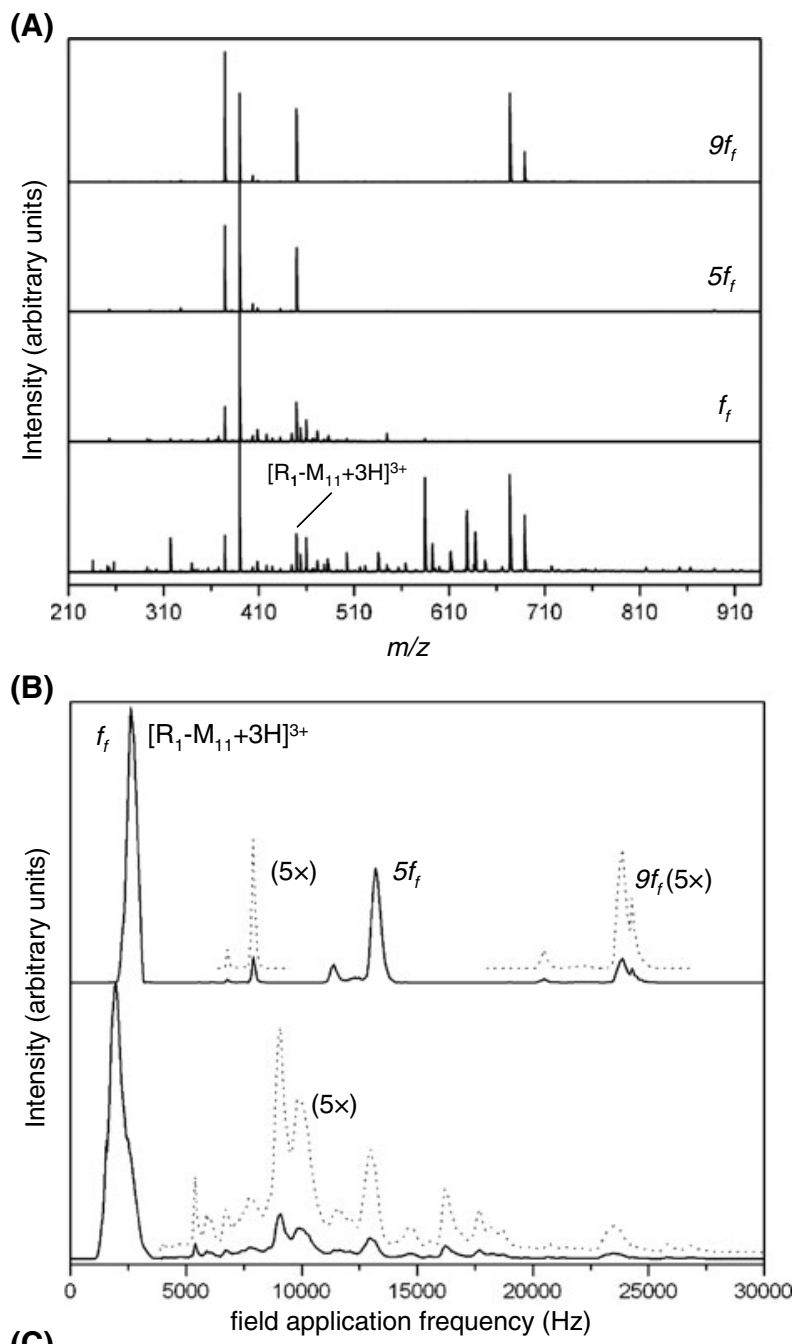

(C)

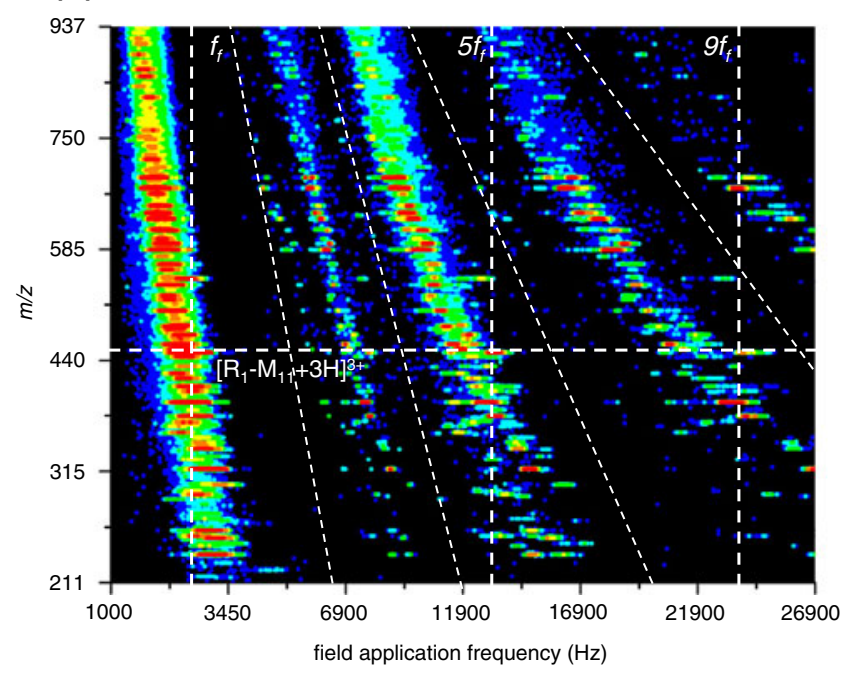


datasets by integrating the ion signal across a given $\mathrm{m} / \mathrm{z}$ range for specific frequency settings. Discussion of OMS and OMS-OMS measurements hereafter refers to this type of treatment; however, it is noted that OMS distributions can be obtained in the absence of MS analysis using the on-axis detector on the instrument (Figure 1A).

The data in Figure 2C show the different frequency ranges over which the fundamental and overtone peaks are observed. In the $f_{f}$ range the average full-width-at-halfmaxima (FWHM) value is $\sim 500 \mathrm{~Hz}$ and the peaks are distributed over $\sim 5000 \mathrm{~Hz}$. Therefore, the calculated peak capacity is $\sim 10$. For the $5 f_{f}$ overtone level, peaks are observed from 7200 to $17200 \mathrm{~Hz}$ - a range of $\sim 10000 \mathrm{~Hz}$. Typically, peak widths are approximately $450 \mathrm{~Hz}$ such that the peak capacity for the $5 f_{f}$ overtone range is $\sim 22$. For the $9 f_{f}$ overtone level, peak widths are approximately $470 \mathrm{~Hz}$ and peaks are observed from 11300 to $29900 \mathrm{~Hz}$, such that the peak capacity is 40 . As observed previously $[1-3,5]$, relative intensities for peaks decrease with increasing frequency.

Figure 2B also shows a comparison of the OMS spectrum for the entire sample and that for the triply-charged Substance $\mathrm{P}$ ion designated hereafter as the $\left[\mathrm{R}_{1}-\mathrm{M}_{11}+\right.$ $3 \mathrm{H}]^{3+}$ peak obtained by extracting data over a narrow $\mathrm{m} / \mathrm{z}$

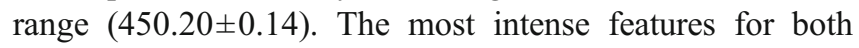
spectra are those observed in the $f_{f}$ region. The $f_{f}$ peak is broader for the mixture distribution than for the $\left[\mathrm{R}_{1}-\mathrm{M}_{11}+\right.$ $3 \mathrm{H}]^{3+}$ ion distribution. This is explained upon examination of the 2D plot (Figure 2C) by the frequency dependence on $\mathrm{m} / \mathrm{z}$ for different species in the mixture. That is, species of lower $\mathrm{m} / \mathrm{z}$ are observed at lower frequencies while species of higher $\mathrm{m} / \mathrm{z}$ are observed at higher frequencies in the $f_{f}$ region. At higher frequencies $(\sim 5000$ to $30000 \mathrm{~Hz})$ peaks are observed nearly across the frequency range of the OMS distribution for the mixture spectrum. For the $\left[\mathrm{R}_{1}-\mathrm{M}_{11}+\right.$ $3 \mathrm{H}]^{3+}$ ion, distribution peak doublets are observed at several different frequency regions. These regions correspond to the $3 f_{f}, 5 f_{f}$, and $9 f_{f}$ regions where the dominant peaks of the doublet are observed at 7920,13224 , and $23855 \mathrm{~Hz}$, with peak widths (FWHM) of 166, 463, and 428, respectively. Here we note that the doublet peaks observed in the different frequency regions for the $\left[\mathrm{R}_{1}-\mathrm{M}_{11}+3 \mathrm{H}\right]^{3+}$ ion correspond to low- and high-mobility gas-phase conformations as observed previously. The relative peak intensities and resolving power dependence on OMS frequency region has been described in detail previously [5].

The mass spectra obtained for different frequency regions are also compared in Figure 2A. The spectrum obtained by summing the signal across all frequency values shows the complexity of the sample; evidence for at least 96 peaks with intensities $>1 \%$ (compared to the base peak) is observed. Mass spectra obtained by selecting a narrow range within a frequency region show considerably fewer peaks. For example, the mass spectrum obtained by taking a narrow slice at the center of the $f_{f}$ peak $(2675 \mathrm{~Hz})$ corresponding to the $\left[\mathrm{R}_{1}-\mathrm{M}_{11}+3 \mathrm{H}\right]^{3+}$ ion shows the majority of peaks occurring from $\mathrm{m} / \mathrm{z}=350$ to 500 . The most abundant peak in this spectrum has been assigned as the $\left[\mathrm{T}_{28}-\mathrm{R}_{38}+2 \mathrm{H}\right]^{2+}$ ion from the cytochrome $c$ protein. The next most abundant ion is assigned to the $\left[\mathrm{R}_{1}-\mathrm{M}_{11}+3 \mathrm{H}\right]^{3+}$ ion. Although many of the higher $\mathrm{m} / \mathrm{z}$ peaks are not observed in this spectrum, for a complex peptide mixture such as the one used in this experiment, ion selection at the $f_{f}$ range inadvertently selects many other ions with similar mobilities. This is due primarily to the low resolving power that is associated with the $f_{f}$ region $[1-3,5]$. To increase the selectivity of the mobility filter, ions through OMS1 must be selected at higher overtone frequencies. This is demonstrated by the mass spectra obtained at the $5 f_{f}$ and $9 f_{f}$ overtone ranges. The $5 f_{f}$ selection has been obtained at $13224 \mathrm{~Hz}$ while the $9 f_{f}$ selection is obtained at $23855 \mathrm{~Hz}$. Here, the mass spectrum obtained at the $5 f_{f}$ range shows 3 major peaks corresponding to the $\left[\mathrm{A}_{40}-\right.$ $\left.\mathrm{R}_{45}+2 \mathrm{H}\right]^{2+},\left[\mathrm{T}_{28}-\mathrm{R}_{38}+2 \mathrm{H}\right]^{2+}$ peptide ions as well as the primary ion of interest, $\left[\mathrm{R}_{1}-\mathrm{M}_{11}+3 \mathrm{H}\right]^{3+}$. Despite the higher OMS resolving power in higher frequency regions, the mass spectrum obtained at the $9 f_{f}$ region shows two additional major peaks (five total). This is due to that fact that two additional ions, $\left[\mathrm{E}_{122}-\mathrm{K}_{133}+2 \mathrm{H}\right]^{2+}$ and $\left[\mathrm{R}_{1}-\mathrm{M}_{11}+2 \mathrm{H}\right]^{2+}$, are selected from the overlapping $13 f_{f}$ range. A complete list of observed peaks is given in Table 1 including the position ( $5 f_{f}$ region $)$ and the FWHM values for each dataset feature.

\section{Separation of Peptides with Similar $\mathrm{m} / \mathrm{z}$ Values}

We have previously demonstrated that OMS can separate isobaric ions if they possess structural differences [1]. This capability has been demonstrated by separating the isobaric carbohydrates, melezitose, and raffinose. Here, we show the separation of the isobaric peptides $\left[\mathrm{H}_{124}-\mathrm{K}_{137}+\right.$ $3 \mathrm{H}]^{3+}(\mathrm{m} / \mathrm{z}=460.285)$ and $\left[\mathrm{E}_{122}-\mathrm{K}_{133}+3 \mathrm{H}\right]^{3+}(\mathrm{m} / \mathrm{z}=460.238)$ from myoglobin and hemoglobin beta chain, respectively. To resolve the monoisotopic peaks from these two peptides a mass spectrometer with a resolving power of 9700 is needed. The mass spectrometer used in this study has a resolving power of $\sim 3500$ to 5000 and, therefore, it cannot distinguish these ions from a mixture. Figure $3 \mathrm{~B}$ shows a select region from the nested two-dimensional frequency $(\mathrm{m} / \mathrm{z})$ plot (Figure 2C). The mass-selected OMS distribution (Figure 3A) shows incomplete resolution of these two ions in the $f_{f}$ region. However, the distribution shows two features in the $3 f_{f}$, $5 f_{f}$, and $9 f_{f}$ regions. The peak center values for the $\left[\mathrm{H}_{124}-\mathrm{K}_{137}+3 \mathrm{H}\right]^{3+}$ ion at $3 f_{f}$, $5 f_{f}$, and $9 f_{f}$ regions are 6891,11490 , and $20710 \mathrm{~Hz}$, respectively, while the peak center values for the $\left[\mathrm{E}_{122}-\right.$ $\left.\mathrm{K}_{133}+3 \mathrm{H}\right]^{3+}$ ion at $3 f_{f}, 5 f_{f}$, and $9 f_{f}$ regions are 7425 , 12370, and $22383 \mathrm{~Hz}$, respectively. The FWHM values for the $\left[\mathrm{H}_{124}-\mathrm{K}_{137}+3 \mathrm{H}\right]^{3+}$ ion at $3 f_{f}, 5 f_{f}$, and $9 f_{f}$ frequencies are 123,365 , and $321 \mathrm{~Hz}$, respectively, while the same values for the $\left[\mathrm{E}_{12}-\mathrm{K}_{133}+3 \mathrm{H}\right]^{3+}$ ion are 161 , 348, and $377 \mathrm{~Hz}$, respectively. The peak resolution values for the two ions at the $3 f_{f}, 5 f_{f}$, and $9 f_{f}$ regions are $1.62,1.30$, and 2.45 , respectively. The identities of these peaks are confirmed by electrospraying tryptic digests of the two proteins separately. 
Table 1. Summary of Observed Peptides for the Three-protein Tryptic Digest using One-dimensional OMS

\begin{tabular}{|c|c|c|c|c|c|}
\hline Protein & Peptide ion $^{\mathrm{a}}$ & $m / z_{\text {calc }}$ & $m / z_{\text {expt }}$ & $5 f_{f}^{\mathrm{b}}$ & $5 f_{f}(\mathrm{FWHM})^{\mathrm{c}}$ \\
\hline \multirow[t]{5}{*}{ Hemoglobin ( $\alpha$-chain) } & {$\left[\mathrm{G}_{58}-\mathrm{K}_{61}+\mathrm{H}\right]^{+}$} & 398.21 & 397.93 & 12977 & 288 \\
\hline & {$\left[\mathrm{M}_{33}-\mathrm{K}_{41}+2 \mathrm{H}\right]^{2+}$} & 536.28 & 536.06 & 10676 & 344 \\
\hline & {$\left[\mathrm{T}_{42}-\mathrm{K}_{57}+3 \mathrm{H}\right]^{3+}$} & 611.97 & 611.75 & 10189 & 353 \\
\hline & {$\left[\mathrm{F}_{129}-\mathrm{K}_{140}+2 \mathrm{H}\right]^{2+}$} & 626.86 & 626.63 & 9470 & 332 \\
\hline & {$\left[\mathrm{T}_{42}-\mathrm{K}_{57}+2 \mathrm{H}\right]^{2+}$} & 917.45 & 917.48 & 7334 & 303 \\
\hline \multirow[t]{13}{*}{ Hemoglobin ( $\beta$-chain) } & {$\left[\mathrm{W}_{134}-\mathrm{K}_{145}+3 \mathrm{H}\right]^{3+}$} & 383.90 & 383.68 & 12844 & 738 \\
\hline & {$\left[\mathrm{E}_{122}-\mathrm{K}_{133}+3 \mathrm{H}\right]^{3+}$} & 460.24 & 459.99 & 12368 & 369 \\
\hline & {$\left[\mathrm{S}_{10}-\mathrm{K}_{18}+2 \mathrm{H}\right]^{2+}$} & 466.76 & 466.50 & 12099 & 364 \\
\hline & {$\left[\mathrm{W}_{134}-\mathrm{K}_{147}+3 \mathrm{H}\right]^{3+}$} & 483.94 & 484.04 & 11831 & 338 \\
\hline & {$\left[\mathrm{V}_{68}-\mathrm{K}_{83}+3 \mathrm{H}\right]^{3+}$} & 557.30 & 557.12 & 10584 & 344 \\
\hline & {$\left[\mathrm{W}_{134}-\mathrm{K}_{145}+2 \mathrm{H}\right]^{2+}$} & 575.34 & 575.04 & 9933 & 335 \\
\hline & {$\left[\mathrm{L}_{106}-\mathrm{K}_{121}+3 \mathrm{H}\right]^{3+}$} & 593.00 & 592.78 & 10403 & 332 \\
\hline & {$\left[\mathrm{K}_{67}-\mathrm{K}_{83}+3 \mathrm{H}\right]^{3+}$} & 600.00 & 600.01 & 9993 & 395 \\
\hline & {$\left[\mathrm{L}_{32}-\mathrm{R}_{41}+2 \mathrm{H}\right]^{2+}$} & 637.87 & 637.64 & 9400 & 401 \\
\hline & {$\left[\mathrm{E}_{122}-\mathrm{K}_{133}+2 \mathrm{H}\right]^{2+}$} & 689.85 & 689.71 & 9178 & 343 \\
\hline & {$\left[\mathrm{W}_{134}-\mathrm{K}_{147}+2 \mathrm{H}\right]^{2+}$} & 725.40 & 725.15 & 8294 & 231 \\
\hline & {$\left[\mathrm{V}_{68}-\mathrm{K}_{83}+2 \mathrm{H}\right]^{2+}$} & 835.45 & 835.34 & 7497 & 273 \\
\hline & {$\left[\mathrm{L}_{106}-\mathrm{K}_{121}+2 \mathrm{H}\right]^{2+}$} & 889.00 & 888.96 & 7446 & 228 \\
\hline \multirow[t]{17}{*}{ Cytochrome $c$} & {$\left[\mathrm{G}_{56}-\mathrm{K}_{60}+2 \mathrm{H}\right]^{2+}$} & 302.68 & 302.45 & 16212 & 478 \\
\hline & {$\left[\mathrm{I}_{9}-\mathrm{K}_{13}+2 \mathrm{H}\right]^{2+}$} & 317.70 & 317.51 & 14732 & 454 \\
\hline & {$\left[\mathrm{K}_{87}-\mathrm{R}_{91}+2 \mathrm{H}\right]^{2+}$} & 331.20 & 330.95 & 15196 & 283 \\
\hline & {$\left[\mathrm{Y}_{74}-\mathrm{K}_{79}+2 \mathrm{H}\right]^{2+}$} & 339.70 & 339.42 & 14258 & 395 \\
\hline & {$\left[\mathrm{K}_{8}-\mathrm{K}_{13}+2 \mathrm{H}\right]^{2+}$} & 381.75 & 381.42 & 13358 & 395 \\
\hline & {$\left[\mathrm{K}_{73}-\mathrm{K}_{79}+2 \mathrm{H}\right]^{2+}$} & 403.74 & 403.47 & 13211 & 351 \\
\hline & {$\left[\mathrm{T}_{28}-\mathrm{K}_{39}+3 \mathrm{H}\right]^{3+}$} & 432.91 & 432.67 & 13005 & 362 \\
\hline & {$\left[\mathrm{G}_{6}-\mathrm{K}_{13}+2 \mathrm{H}\right]^{2+}$} & 474.31 & 474.46 & 11004 & 322 \\
\hline & {$\left[\mathrm{H}_{26}-\mathrm{R}_{38}+3 \mathrm{H}\right]^{3+}$} & 478.60 & 478.95 & 11216 & 400 \\
\hline & {$\left[\mathrm{E}_{92}-\mathrm{K}_{99}+2 \mathrm{H}\right]^{2+}$} & 482.77 & 482.48 & 11198 & 366 \\
\hline & {$\left[\mathrm{H}_{26}-\mathrm{K}_{39}+3 \mathrm{H}\right]^{3+}$} & 521.30 & 521.60 & 10515 & 354 \\
\hline & {$\left[\mathrm{I}_{9}-\mathrm{K}_{22}+3 \mathrm{H}\right]^{3+}$} & 545.28 & 545.03 & 12699 & 465 \\
\hline & {$\left[\mathrm{E}_{92}-\mathrm{K}_{100}+2 \mathrm{H}\right]^{2+}$} & 546.82 & 546.54 & 10692 & 312 \\
\hline & {$\left[\mathrm{T}_{28}-\mathrm{R}_{38}+2 \mathrm{H}\right]^{2+}$} & 584.82 & 584.50 & 10096 & 413 \\
\hline & {$\left[\mathrm{T}_{40}-\mathrm{K}_{53}+2 \mathrm{H}\right]^{2+}$} & 735.85 & 735.67 & 9074 & 280 \\
\hline & {$\left[\mathrm{K}_{39}-\mathrm{K}_{53}+2 \mathrm{H}\right]^{2+}$} & 799.89 & 799.80 & 8645 & 577 \\
\hline & {$\left[\mathrm{I}_{9}-\mathrm{K}_{22}+2 \mathrm{H}\right]^{2+}$} & 817.41 & 817.20 & 8703 & 353 \\
\hline \multirow[t]{12}{*}{ Myoglobin } & {$\left[\mathrm{H}_{22}-\mathrm{K}_{28}+3 \mathrm{H}\right]^{3+}$} & 245.83 & 245.69 & 16211 & 484 \\
\hline & {$\left[\mathrm{F}_{56}-\mathrm{K}_{61}+2 \mathrm{H}\right]^{2+}$} & 342.69 & 342.39 & 14205 & 392 \\
\hline & {$\left[\mathrm{H}_{22}-\mathrm{K}_{28}+2 \mathrm{H}\right]^{2+}$} & 368.25 & 367.97 & 12324 & 308 \\
\hline & {$\left[\mathrm{L}_{46}-\mathrm{K}_{53}+3 \mathrm{H}\right]^{3+}$} & 424.56 & 424.28 & 11791 & 360 \\
\hline & {$\left[\mathrm{H}_{124}-\mathrm{K}_{137}+3 \mathrm{H}\right]^{3+}$} & 460.29 & 459.99 & 11493 & 369 \\
\hline & {$\left[\mathrm{T}_{43}-\mathrm{K}_{53}+3 \mathrm{H}\right]^{3+}$} & 493.92 & 493.72 & 11849 & 272 \\
\hline & {$\left[\mathrm{H}_{8}-\mathrm{K}^{19}+3 \mathrm{H}\right]^{3+}$} & 502.98 & 502.70 & 11623 & 395 \\
\hline & {$\left[\mathrm{Y}_{6}-\mathrm{K}_{21}+3 \mathrm{H}\right]^{3+}$} & 629.01 & 628.73 & 9807 & 330 \\
\hline & {$\left[\mathrm{L}_{46}-\mathrm{K}_{53}+2 \mathrm{H}\right]^{2+}$} & 636.34 & 636.07 & 9561 & 511 \\
\hline & {$\left[\mathrm{K}_{138}-\mathrm{K}_{149}+2 \mathrm{H}\right]^{2+}$} & 753.97 & 753.78 & 8086 & 275 \\
\hline & {$\left[\mathrm{V}_{29}-\mathrm{R}_{42}+2 \mathrm{H}\right]^{2+}$} & 803.93 & 803.82 & 8135 & 396 \\
\hline & {$\left[\mathrm{Y}_{6}-\mathrm{K}_{21}+2 \mathrm{H}\right]^{2+}$} & 943.01 & 943.01 & 6733 & 205 \\
\hline
\end{tabular}

${ }^{a}$ Amino acid sequence for each peptide is reported starting with the N-terminus one letter code with its position number in the protein followed by the Cterminus one letter code with its position number. The position number is reported as a subscript next to the amino acid.

The $m / z_{\text {calc }}$ values reported here are based on the theoretical values for the monoisotopic mass.

${ }^{\mathrm{b}}$ Frequency for the $5 f_{f}$ overtone peak (center) for all ions are given in the units of $\mathrm{Hz}$, and the frequency values reported here are for non-activated species.

${ }^{\mathrm{c}}$ The full width at half maximum (FWHM) values for the $5 f_{f}$ overtone peaks are given in the units of $\mathrm{Hz}$.

\section{Two-dimensional OMS: Selection, Activation,} and Detection of the Substance P Peptide Ion

Although the resolving power of OMS at higher overtone regions is considerably high (i.e., comparable to IMS), it is still not sufficient to completely isolate a given precursor ion from other mixture ions prior to MS analysis. For example, even though the two ions mentioned earlier are separated from each other, there are many other ions that overlap with these two ions in the frequency space. This is determined by obtaining mass spectral slices at the centers (frequency dimension) of the two peaks. Therefore, it is rather difficult to carry out collision-induced dissociation (CID) of mobility isolated ions for such complex samples with this technique. Similar to recently developed IMSIMS techniques [21-23], a two-dimensional OMS technique (OMS-OMS) could improve the overall peak capacity of the separation and thereby reduce the overlap problem for OMS-CID/MS analysis. The foundational, tandemIMS method is based on the fact that the gas phase structures of biomolecules can be changed by CA. Here, ions are selected after the OMS1 drift tube using an ion gate and subjected to CA before entering the OMS2 drift region. Under favorable conditions, the activated ions 


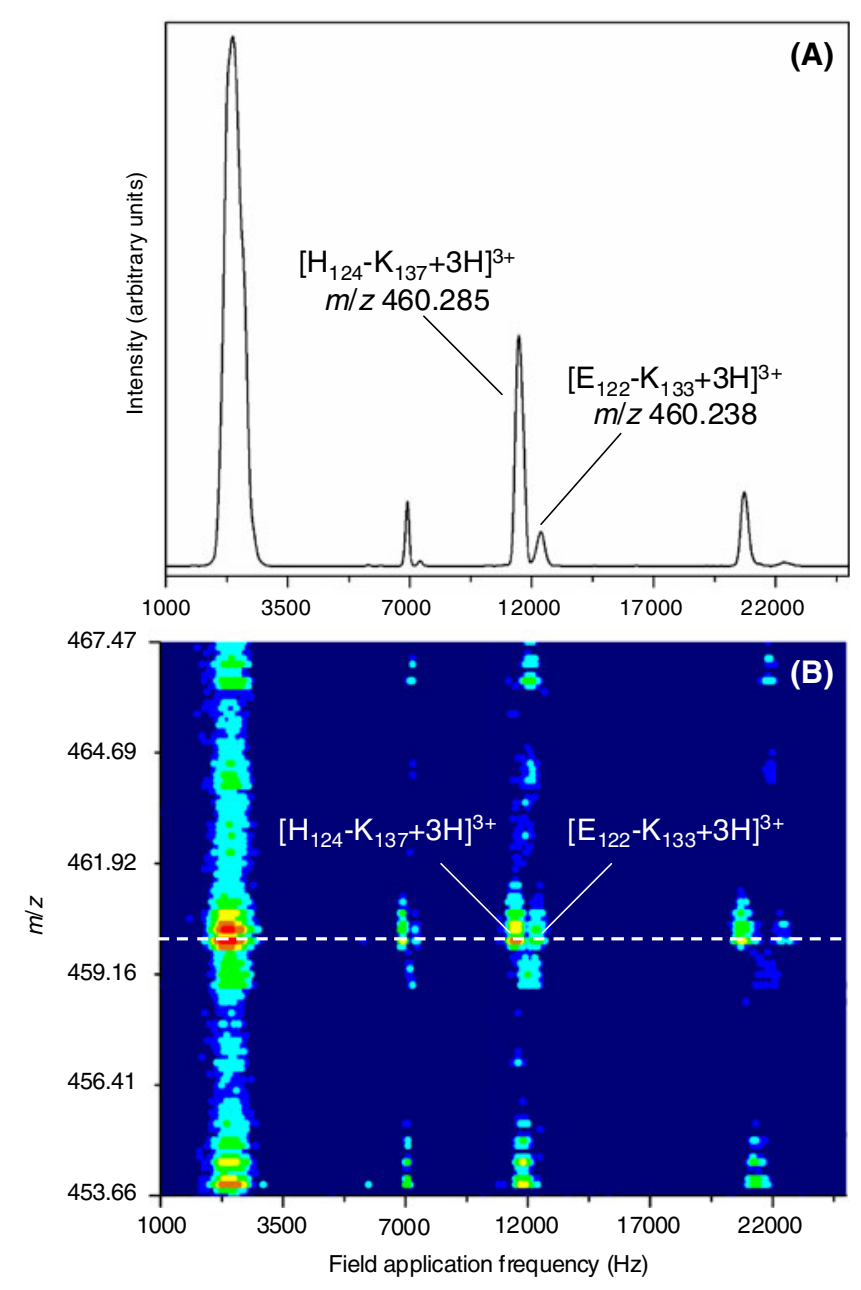

Figure 3. Panel (B) shows a selected region of the nested two-dimensional frequency $(\mathrm{m} / \mathrm{z})$ plot (Figure $2 \mathrm{C}$ ) obtained upon electrospraying a three-protein tryptic digest with spiked Substance P. The 2D plot shows the frequency separation of two peptides from the myoglobin and hemoglobin beta-chain proteins with nearly identical theoretical $\mathrm{m} / \mathrm{z}$ values $(460.285$ and 460.238, respectively). The OMS spectrum obtained by taking a slice across $\mathrm{m} / \mathrm{z} 459.99 \pm 0.14$ is shown in (A). The $\mathrm{m} / \mathrm{z}$ value for the experimentally observed peak is 459.99 . The two peaks observed in the OMS spectrum show the separation of the two peptides in the $3 f_{f}$, $5 f_{f}$, and $9 f_{f}$ frequency regions

possess significantly different collision cross sections and thereby get separated from other ions with similar initial structures. Also, under these conditions, different ions experience a wide range of conformational change resulting in a considerable increase in separation capacity for complex mixtures. The same basic principle can be applied to OMS due to the fact that the ion separation in OMS is also based on differences in the collision cross sections (or mobilities) of the gas phase ions.

Figures $4 \mathrm{~B}$ and $4 \mathrm{C}$ show the two-dimensional frequency $(\mathrm{m} / \mathrm{z})$ plots for a tryptic digest sample containing the Substance $\mathrm{P}$ peptide before and after, respectively, employing CA. The data shown in Figure 4 is obtained by
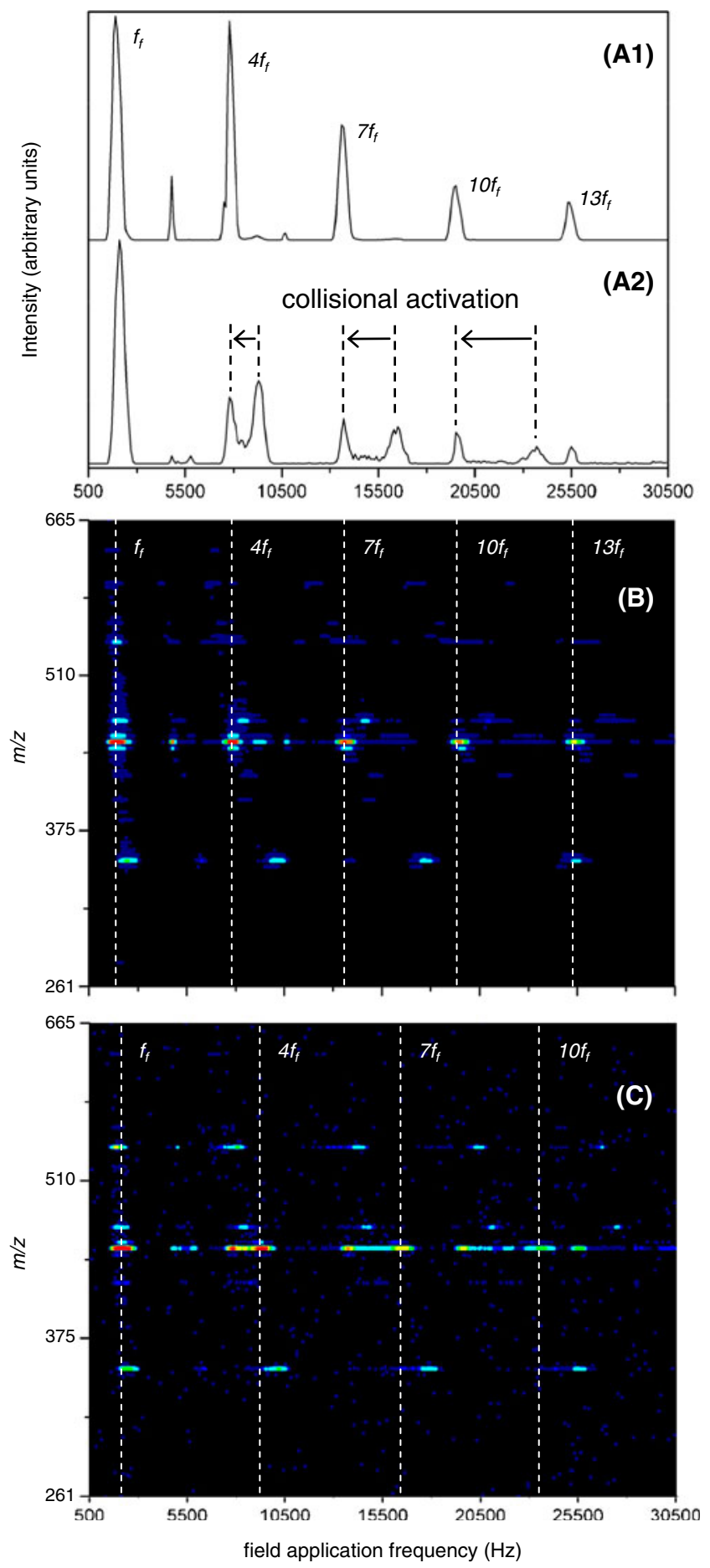

Figure 4. Nested two-dimensional frequency $(\mathrm{m} / \mathrm{z})$ plots (B) and (C) obtained upon electrospraying a solution of Substance $\mathrm{P}$ and the OMS spectra (A) obtained for the same sample. When the activation field at the back of the F2 funnel is increased to $>500 \mathrm{~V} \cdot \mathrm{cm}^{-1}$, the $[\mathrm{M}+3 \mathrm{H}]^{3+}$ ion acquires an extended structure (Figure 4A1). When the activation field is $17 \mathrm{~V} \cdot \mathrm{cm}^{-1}$, both extended and compact structures can be seen (4A2). Figure (B) is obtained using a $504 \mathrm{~V} \cdot \mathrm{cm}^{-1}$ activation field while $(\mathbf{C})$ is obtained using a $17 \mathrm{~V} \cdot \mathrm{cm}^{-1}$ activation field. The dotted lines on both (B) and (C) correspond to the fundamental and other overtone peaks for the $[\mathrm{M}+3 \mathrm{H}]^{3+}$ ion 
operating the instrument in the OMS-OMS-MS mode. Here, the OMS1 drift tube is operated at $2675 \mathrm{~Hz}$ (using a four-phase wave driver) to select the $\left[\mathrm{R}_{1}-\mathrm{M}_{11}+3 \mathrm{H}\right]^{3+}$ ion. At this field application frequency, one major ion $\left(\left[\mathrm{R}_{1}-\mathrm{M}_{11}+3 \mathrm{H}\right]^{3+}\right)$ and four other unidentified ions $(\mathrm{m} / \mathrm{z}$ $352.09,455.58,469.27$, and 542.24) with peak intensities ranging between $1 \%$ to $8 \%$ of the base peak height are stable through the OMS1 region. The selected ions then enter the OMS2 region through the F2 ion funnel (Figure 1A). The OMS2 drift tube is operated using a three-phase wave driver and therefore the observation of the $4 f_{f}, 7 f_{f}$, and $10 f_{f}$ etc. peaks in the OMS spectrum is expected. This spectrum is obtained by scanning the field application frequency from $500 \mathrm{~Hz}$ to approximately $36000 \mathrm{~Hz}$ in $100 \mathrm{~Hz}$ steps. In this experiment, the precursor ion selected by the OMS1 region and transmitted to the OMS2 region does not undergo $\mathrm{CA}$ $(\Delta \rightarrow \Delta \rightarrow O)$. The OMS distribution for the $\left[\mathrm{R}_{1}-\mathrm{M}_{11}\right.$ $+3 \mathrm{H}]^{3+}$ ion shows two distinct peaks for all the overtone levels (Figure 4A2). This is due to the fact that under these field conditions in the IA region $\left(17 \mathrm{~V} \cdot \mathrm{cm}^{-1}\right.$ corresponding to no activation), both extended and compact conformations for the $\left[\mathrm{R}_{1}-\mathrm{M}_{11}+3 \mathrm{H}\right]^{3+}$ ion are stable in the drift tube. The peak centers for the extended conformation at the $4 f_{f}, 7 f_{f}, 10 f_{f}$, and $13 f_{f}$ frequency regions are $7883,13724,19616$, and $25531 \mathrm{~Hz}$, respectively. The peak centers for the compact conformation at the first three regions $\left(4 f_{f}, 7 f_{f}\right.$, and $\left.10 f_{f}\right)$ are 9296, 16431, and $23665 \mathrm{~Hz}$, respectively. Note that the extended conformation occurs at a lower frequency compared to the compact structure due to the inverse relationship between the drift time and the frequency. The peak resolution in the $4 f_{f}, 7 f_{f}$, and $10 f_{f}$ regions for the two conformations is $1.12,2.23$, and 3.26 , respectively. When the activation field is increased to $>500 \mathrm{~V} \cdot \mathrm{cm}^{-1}$, all ions exhibiting compact conformations are converted to the extended structure (Figure 4A1). Here, in addition to the ions observed in the low activation energy experiment, two other peaks are observed in the mass spectrum that correspond to $\left[\mathrm{R}_{1}\right.$ $\left.-\mathrm{M}_{11}+3 \mathrm{H}-\mathrm{NH}_{3}\right]^{3+}$ and $\left[\mathrm{R}_{1}-\mathrm{M}_{11}+2 \mathrm{H}\right]^{2+}$ ions. These results suggest that the ion activation can shift dataset features in the frequency space and thereby provide additional separation capacity in OMS-OMS-MS experiments of the form $\Delta \stackrel{\mathrm{CA}}{\rightarrow} \Delta \rightarrow \mathrm{O}$.

\section{Substance P Peptide Ion Selection at the $f_{f}$ Range}

The OMS-OMS experiment described above has been carried out using a complex three-protein tryptic digest spiked with the Substance P peptide. Separations for this system are investigated because it provides a fairly complex mixture with a standard peptide whose peak positions for nonactivated and activated species are known. Figure 5C shows a nested two-dimensional frequency $(\mathrm{m} / \mathrm{z})$ plot for this sample. Here, the $\left[\mathrm{R}_{1}-\mathrm{M}_{11}+3 \mathrm{H}\right]^{3+}$ ion is selected in the
OMS1 drift tube by applying a constant frequency $(2675 \mathrm{~Hz})$ and subjected to CA before entering the second OMS region by applying a $500 \mathrm{~V} \cdot \mathrm{cm}^{-1}$ field at the end of $\mathrm{F} 2$ $(\Delta \stackrel{\mathrm{CA}}{\rightarrow} \triangle \rightarrow \mathrm{O}$ ). The total mass spectrum (bottom spectrum in Figure $5 \mathrm{~A}$ ) obtained at this frequency shows two major peaks corresponding to the $\left[\mathrm{T}_{28}-\mathrm{R}_{38}+3 \mathrm{H}\right]^{3+}$ ion from cytochrome $c$ and the $\left[\mathrm{R}_{1}-\mathrm{M}_{11}+3 \mathrm{H}\right]^{3+}$ ion. Also, at least eight other peaks are observed with much lower intensities. The OMS spectrum obtained by summing the signal across all $\mathrm{m} / \mathrm{z}$ values is given in Figure 5B (bottom trace). This OMS spectrum shows two major peaks at each overtone range that correspond to the two major ions identified in the mass spectrum as well as low intensity peaks that are due to other ions of lower intensity. In contrast, the top distribution in Figure 5B shows the OMS spectrum obtained by extracting data over a narrow $\mathrm{m} / \mathrm{z}$ range $(450.20 \pm 0.14)$. Here we note that such an extracted ion OMS distribution serves several purposes including the ability to distinguish peaks in the total OMS spectrum as well as for comparison to the OMS spectrum obtained for the standard peptide.

Although the total mass spectrum showed two major peaks in addition to several low intensity peaks, the mass spectral slices obtained at different overtone regions show that the $\left[\mathrm{R}_{1}-\mathrm{M}_{11}+3 \mathrm{H}\right]^{3+}$ ion is the only major peak (Figure 5A). The two minor peaks observed in most of these mass spectra correspond to the $\left[\mathrm{H}_{124}-\mathrm{K}_{137}+3 \mathrm{H}\right]^{3+}$ ion from myoglobin and the $\left[\mathrm{R}_{1}-\mathrm{M}_{11}+3 \mathrm{H}-\mathrm{NH}_{3}\right]^{3+}$ ion. At lower $\mathrm{m} / z$ values, the two additional ions observed in the mass spectrum obtained at the $13 f_{f}$ region result from overlap of ions from the $10 f_{f}$ region. The plots in Figure 5 demonstrate the selection of a single ion from a complex mixture prior to MS analysis using the OMS-OMS technique.

\section{Substance P Peptide Ion Selection at the $13 f_{f}$ Overtone Frequency Range}

The selection of ions in both OMS regions can be carried out at any one of the overtone frequency ranges. At higher overtone levels, the resolving power is higher and, therefore, the selectivity is also higher. The example above shows the resolution that is achieved with the use of ion selection at the $f_{f}$ region. Here we demonstrate improved selectivity with the use of higher frequency selections. Figure $6 \mathrm{C}$ shows the nested two-dimensional frequency $(m / z)$ plot for the $\left[\mathrm{R}_{1}-\mathrm{M}_{11}+3 \mathrm{H}\right]^{3+}$ ion selection at the $13 f_{f}$ overtone level $(33800 \mathrm{~Hz})$ in OMS1. Here we note that the frequency that is used to select this ion is not the center of the peak in the OMS distribution; rather the selection is slightly to the left side of the peak. The choice of the selection frequency is carefully determined to reduce the selection of the $\left[\mathrm{T}_{28}-\mathrm{R}_{38}+3 \mathrm{H}\right]^{3+}$ ion. Figure 6 shows the dramatic reduction in the number of peaks observed in the $2 \mathrm{D}$ plot. The total mass spectrum shows one major peak and two other minor peaks 

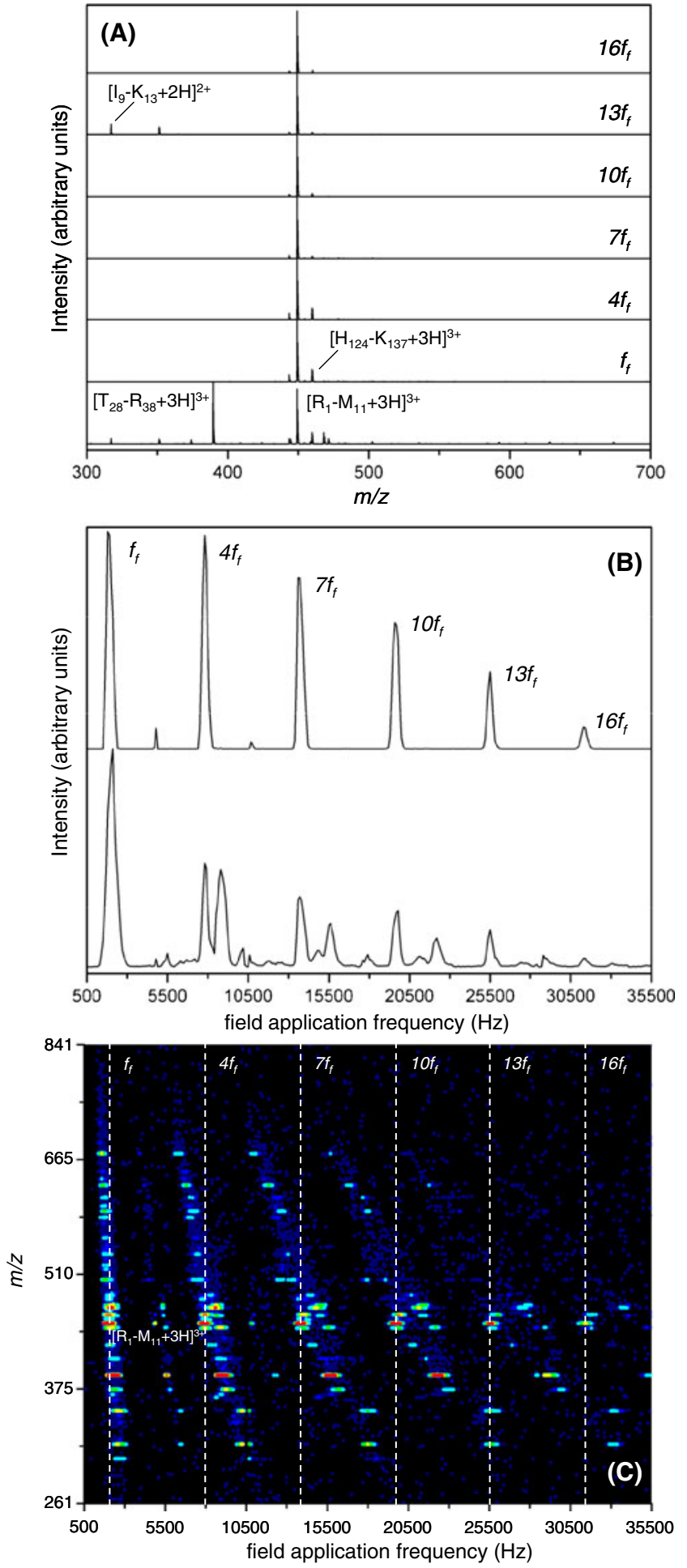

(bottom trace in Figure 6A). The two minor peaks correspond to the $\left[\mathrm{T}_{28}-\mathrm{R}_{38}+3 \mathrm{H}\right]^{3+}$ ion from cytochrome $c$ and the $\left[\mathrm{A}_{40}-\mathrm{R}_{45}+2 \mathrm{H}\right]^{2+}$ ion from myoglobin. Also, a very low intensity peak at $\mathrm{m} / \mathrm{z}=$ 444.52 is observed and corresponds to the loss of ammonia from the $\left[\mathrm{R}_{1}-\mathrm{M}_{11}+3 \mathrm{H}\right]^{3+}$ ion. The total OMS spectrum and the OMS spectrum obtained at $m / z=450.20 \pm 0.14$ (Figure 6B) also shows the improved selectivity gained by selecting at a higher overtone range in OMS1. Using
Figure 5. Panel (C) shows a nested two-dimensional frequency $(\mathrm{m} / \mathrm{z})$ plot obtained upon electrospraying a threeprotein tryptic digest with spiked Substance P peptide. Here, the OMS1 region is operated using a four-phase wave driver and the frequency is fixed at $2675 \mathrm{~Hz}$ to select the $[\mathrm{M}+3 \mathrm{H}]^{3+}$ ion of Substance $\mathrm{P}$ (fundamental peak). The selected ion is activated at the back of the F2 ion funnel before entering the OMS2 region. The OMS2 region is operated using a threephase wave driver and the frequency is scanned from 500 to $\sim 36000 \mathrm{~Hz}$ to obtain the OMS spectrum. The dotted lines correspond to the peak centers for the $f_{f}$ and other overtone peaks for the $[\mathrm{M}+3 \mathrm{H}]^{3+}$ ion of Substance $\mathrm{P}$. The OMS spectra (B) and the mass spectra (A) obtained for the same sample are also given. The bottom OMS spectrum $(\mathbf{B})$ is the total spectrum obtained by summing the signal for all $\mathrm{m} / \mathrm{z}$ values, and the top spectrum, upper trace in (B) corresponds to the $[\mathrm{M}+3 \mathrm{H}]^{3+}$ ion of Substance $\mathrm{P}$. The bottom mass spectrum $(\mathbf{A})$ is obtained by integrating the signal across the whole frequency range. The mass spectra labeled $f_{f}$, $4 f_{f}, 7 f_{f}, 10 f_{f}, 13 f_{f}$, and $16 f_{f}$ (A) are obtained by taking slices through the centers of the $f_{f}, 4 f_{f} ; 7 f_{f}, 10 f_{f} ; 13 f_{f}$, and $16 f_{f}$ frequency peaks, for the $[\mathrm{M}+3 \mathrm{H}]^{3+}$ ion of Substance $\mathrm{P}$, respectively

this technique, it is possible to completely isolate a single ion from a complex peptide mixture as shown in the mass spectra obtained at the $f_{f}$ and other overtone regions (Figure 6A).

\section{Estimating the Peak Capacity for OMS-OMS Measurements}

The peak capacities for the different OMS spectral regions have been estimated above. Values of $\sim 10,22$, and 40 are obtained for the $f_{f}, 5 f_{f}$, and $10 f_{f}$ regions, respectively. These values are very similar to the average OMS resolving power ( $\left.R_{O M S}\right)$ of each region $(\sim 5,27$, and 42 , respectively). Using values obtained from the theoretical expression of $R_{O M S}[2$, 5], it is possible to estimate the peak capacity for the isolation shown in Figure 6. For the purposes of determining an upper limit for these experiments, a process that includes selection at the $13 f_{f}$ and $16 f_{f}$ overtone regions for OMS1 and OMS2 selections, respectively, is employed. Calculated values of $R_{O M S}$ for these frequency regions are 48 and 68, respectively. Considering the fact that collisional activation of peptide ions results in changes in collision cross section that are on the order of $\sim \pm 10 \%$ (on the high end) an upper end estimate of the OMS-OMS peak capacity for this isolation experiment would be 653. A note of caution should be provided with this estimate because, as shown above, overlap of ions from flanking frequency regions can decrease the overall peak capacity. That said, assuming nearly $25 \%$ overlap of the $13 f_{f}$ region with peaks from the $9 f_{f}$ and the $17 f_{f}$ regions, the OMS-OMS peak capacity would still be $\sim 500$. The best indication of the high peak capacity afforded by the new instrument is the near complete isolation of Substance P peptide ion even employing only the $4 f_{f}$ selection in the OMS2 region as shown in Figure 6A. 
Figure 6. Panel (C) shows a nested two-dimensional frequency $(\mathrm{m} / \mathrm{z})$ plot obtained upon electrospraying a threeprotein tryptic digest with spiked Substance $P$ peptide. Here, the OMS1 region is operated using a four-phase wave driver and the frequency is fixed at $33800 \mathrm{~Hz}$ to select the Substance $\mathrm{P}[\mathrm{M}+3 \mathrm{H}]^{3+}$ ion (13 $f_{f}$ region). The selected ion is activated at the back of the $\mathrm{F} 2$ ion funnel before entering the OMS2 region. The OMS2 region is operated using a three-phase wave driver and the frequency is scanned from 500 to $\sim 36000 \mathrm{~Hz}$ to obtain the OMS spectrum. The dotted lines correspond to the peak centers for the fundamental and other overtone peaks for the $[\mathrm{M}+3 \mathrm{H}]^{3+}$ ion of Substance $\mathrm{P}$. The OMS spectra (B) and the mass spectra (A) obtained for the same sample are also given. The bottom OMS spectrum, lower trace in $(\mathbf{B})$, is the total spectrum obtained by summing the signal for all $\mathrm{m} / \mathrm{z}$ values, and the top spectrum, upper trace in (B), corresponds to the $[\mathrm{M}+3 \mathrm{H}]^{3+}$ ion of Substance $P$. The bottom mass spectrum $(\mathbf{A})$ is obtained by integrating the signal across the whole frequency range. The mass spectra labeled $f_{f}, 4 f_{f}, 7 f_{f}, 10 f_{f}, 13 f_{f}$, and $16 f_{f}$ (A) are obtained by taking slices through the centers of the $f_{f}, 4 f_{f}, 7 f_{f}, 10 f_{f}, 13 f_{f}$, and $16 f_{f}$ frequency peaks, for the $[\mathrm{M}+3 \mathrm{H}]^{3+}$ ion of Substance $\mathrm{P}$, respectively

It is instructive to consider methods to improve the overall peak capacity. Because $R_{O M S}$ scales directly with frequency $[1-3,5]$, operation of OMS1 and/or OMS2 at higher overtone regions should substantially improve the peak capacity. Previously a $R_{O M S}$ value of 220 has been reported for measurements performed with a linear OMS device operating at the $33 f_{f}$ region [3]. That said, improvements in peak capacity come at a cost to sensitivity resulting from lower ion transmission at higher frequencies (e.g., see Figure 2B) [1, 2, 5].

\section{The Versatility of the OMS-OMS Approach}

As described above, the OMS-OMS measurement can be carried out at moderately low pressures. Because the separation is based on ion mobilities, this approach can be extended to any pressure regime that can be employed for IMS separations. Thus, such measurements can be carried out at higher pressures allowing the use of higher fields in the drift tubes. This would serve to increase the overall $R_{O M S}$ $[2,5]$. Additionally, the high resolution approach can be used with and without MS detection. That is, depending on the complexity of the mixture sample, the high resolution afforded by OMS-OMS devices that are not coupled to MS may be sufficient to identify specific sample components. Finally, ion activation resulting in precursor fragmentation can be employed. Here, mobility isolation of precursor ions can be coupled with the isolation of fragments according to their mobilities. Such an approach provides another means for improving the selectivity of the analysis. Thus, different OMS-OMS strategies can be tailored to the sample separation requirements.
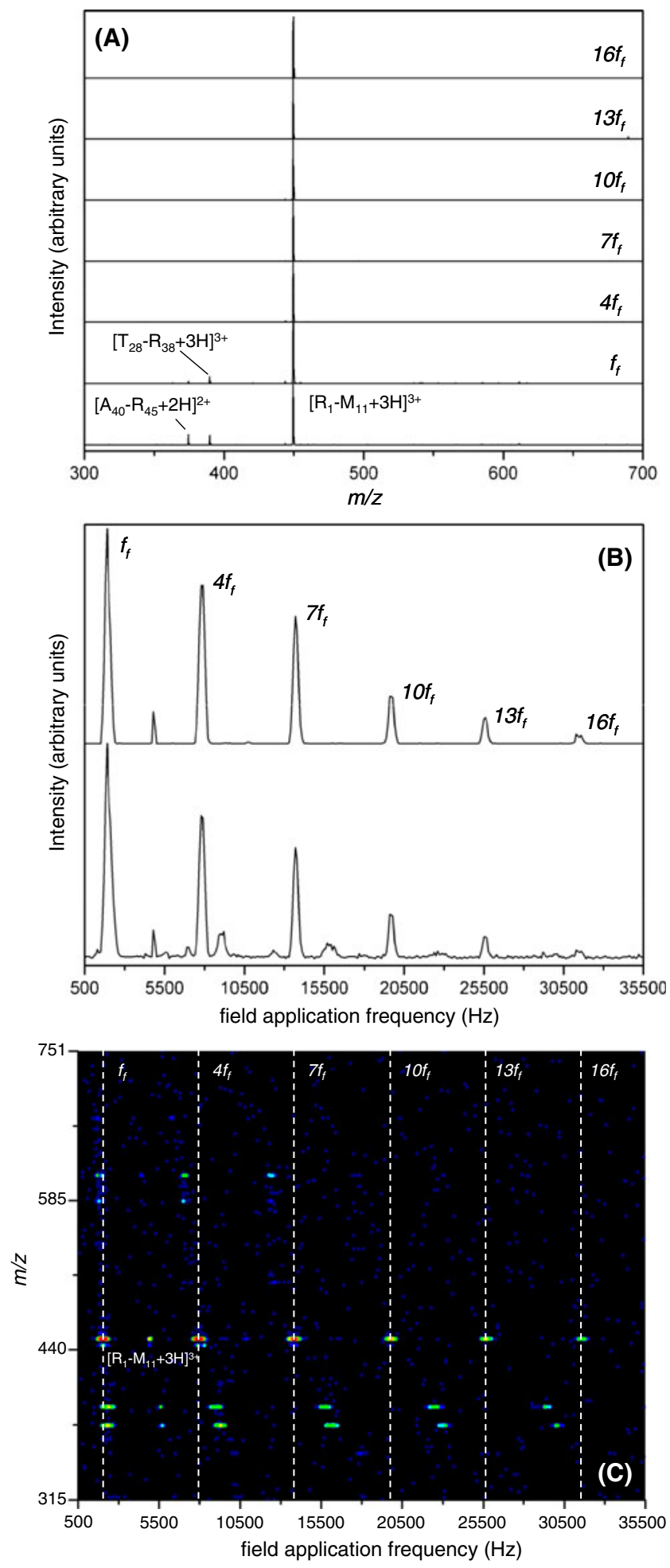

\section{Summary}

The development of the first OMS-OMS instrument and its utility in analyzing a complex tryptic peptide mixture has been described. Isolation of the Substance P $[\mathrm{M}+3 \mathrm{H}]^{3+}$ ion from other components in this complex mixture without using prior condensed-phase separation steps has been demonstrated. It is 
estimated that significant peak capacity (comparable to IMSIMS techniques) can be obtained with the OMS-OMS approach. The improved ion selection realized by OMS-OMS serves as a complement for MS analyses. Additionally, the ability to utilize conformational transformations as well as ion fragmentation provides increased flexibility for identifying sample components. Although here we have demonstrated the utility of OMSOMS methods for peptide analysis, it should be relatively straightforward to extend it to the analysis of other biomolecules such as carbohydrates, polymers, and lipids. A unique feature of this method over conventional IMS is the ability to select the overtone level to suit the experiment. That is, the selection process and the associated peak capacity are more tunable to the desired experiment.

\section{Acknowledgments}

The authors acknowledge support in part for the development of new instrumentation by grants from the National Institutes of Health (AG-024547-01 and P41-RR018942), and the METACyt initiative funded by a grant from the Lilly Endowment. The authors thank John Poehlman and Andrew Alexander for technical support.

\section{References}

1. Kurulugama, R.T., Nachtigall, F.M., Lee, S., Valentine, S.J., Clemmer, D.E.: Overtone Mobility Spectrometry (Part 1): Experimental Observations. J. Am. Soc. Mass Spectrom. 20(5), 729-737 (2009)

2. Valentine, S.J., Stokes, S.T., Kurulugama, R.T., Nachtigall, F.M., Clemmer, D.E.: Overtone Mobility Spectrometry (Part 2): Theoretical Considerations of Resolving Power. J. Am. Soc. Mass Spectrom. 20(5), 738-750 (2009)

3. Lee, S., Ewing, M.A., Nachtigall, F.M., Kurulugama, R.T., Valentine, S.J., Clemmer, D.E.: Determination of Cross Sections by Overtone Mobility Spectrometry: Evidence for Loss of Unstable Structures at Higher Overtones. J. Phys. Chem. B, 114(38), 12406-12415 (2010)

4. Glaskin, R.S., Valentine, S.J., Clemmer, D.E.: A Scanning Frequency Mode for Ion Cyclotron Mobility Spectrometry. Anal. Chem. 82(19), 8266-8271 (2010)

5. Valentine, S.J., Kurulugama, R.T., Clemmer, D.E.: Overtone Mobility Spectrometry: Part 3. On the Origin of Peaks. J. Am. Soc. Mass Spectrom. 22(5), 804-816 (2011)

6. St Louis, R.H., Hill Jr., H.H.: Ion Mobility Spectrometry in Analytical Chemistry. Crit. Rev. Anal. Chem. 21, 321-355 (1990)

7. Clemmer, D.E., Jarrold, M.F.: Ion Mobility Measurements and Their Applications to Clusters and Biomolecules. J. Mass Spectrom. 32, 577592 (1997)

8. Collins, D.C., Lee, M.L.: Developments in Ion Mobility SpectrometryMass Spectrometry. Anal. Bioanal. Chem. 372, 66-73 (2002)

9. Hoaglund-Hyzer, C.S., Counterman, A.E., Clemmer, D.E.: Anhydrous Protein Ions. Chem. Rev. 99, 3037-3079 (1999)

10. Revercomb, H.E., Mason, E.A.: Theory of Plasma Chromatography/ Gaseous Electrophoresis. Anal. Chem. 47, 970-983 (1975)

11. Cohen, M.J., Karasek, F.W.J.: Chromatogr. Sci. 8, 330 (1970)

12. Liu, X., Valentine, S.J., Plasencia, M.D., Trimpin, S., Naylor, S., Clemmer, D.E.: Mapping the Human Plasma Proteome by SCX-LCIMS-MS. J. Am. Soc. Mass Spectrom. 18, 1249-1264 (2007)

13. Valentine, S.J., Counterman, A.E., Hoaglund, C.S., Reilly, J.P., Clemmer, D.E.: Gas-Phase Separations of Protease Digests. J. Am. Soc. Mass Spectrom. 9, 1213-1216 (1998)

14. Matz, L.M., Dion, H.M., Hill, H.H.: Evaluation of Capillary Liquid Chromatography-Electrospray Ionization Ion Mobility Spectrometry with Mass Spectrometry Detection. J. Chromatogr. A 946(1/2), 59-68 (2002)

15. Ruotolo, B.T., Gillig, K.J., Stone, E.G., Russell, D.H.: Peak Capacity of Ion Mobility Mass Spectrometry: Separation of Peptides in Helium Buffer gas. J. Chromatogr. B 782(1/2), 385-392 (2002)

16. McLean, J.A., Ruotolo, B.T., Gillig, K.J., Russell, D.H.: Ion MobilityMass Spectrometry: A New Paradigm for Proteomics. Int. J. Mass Spectrom. 240(3), 301-315 (2005)

17. McLean, J.A., Ridenour, W.B., Caprioli, R.M.: Profiling and Imaging of Tissues by Imaging Ion Mobility-Mass Spectrometry. J. Mass Spectrom. 42(8), 1099-1105 (2007)

18. Shvartsburg, A.A., Jarrold, M.F.: An Exact Hard-Spheres Scattering Model for the Mobilities of Polyatomic Ions. Chem. Phys. Lett. 261, 86-91 (1996)

19. Mesleh, M.F., Hunter, J.M., Shvartsburg, A.A., Schatz, G.C., Jarrold, M.F.: Structural Information from Ion Mobility Measurements: Effects of the Long-Range Potential. J. Phys. Chem. 100, 16082-16086 (1996)

20. Wyttenbach, T., Von Helden, G., Batka Jr., J.J., Carlat, D., Bowers, M. T.: Effect of the Long-Range Potential on Ion Mobility Measurements. J. Am. Soc. Mass Spectrom. 8, 275-282 (1997)

21. Koeniger, S.L., Merenbloom, S.I., Valentine, S.J., Jarrold, M.F., Udseth, H.R., Smith, R.D., Clemmer, D.E.: An IMS-IMS Analogue of MS-MS. Anal. Chem. 78, 4161-4174 (2006)

22. Merenbloom, S.I., Koeniger, S.L., Valentine, S.J., Plasencia, M.D., Clemmer, D.E.: IMS-IMS and IMS-IMS-IMS/MS for Separating Peptide and Protein Fragment Ions. Anal. Chem. 78, 2802-2809 (2006)

23. Merenbloom, S.I., Bohrer, B.C., Koeniger, S.L., Clemmer, D.E.: Assessing the Peak Capacity of IMS-IMS Separations of Tryptic Peptide Ions in 300 K He. Anal. Chem. 79, 515-522 (2007)

24. Gallien, S., Duriez, E., Domon, B.: Selected Reaction Monitoring Applied to Proteomics. J. Mass. Spectrom. 46, 298-312 (2011)

25. Mason, E.A., McDaniel, E.W.: Transport Properties of Ions in Gases. Wiley, New York (1988)

26. Myung, S., Badman, E.R., Lee, Y.J., Clemmer, D.E.: Structural Transitions of Electrosprayed Ubiquitin Ions Stored in an Ion Trap over $10 \mathrm{~ms}$ to 30 s. J. Phys. Chem. A 106, 9976-9982 (2002)

27. Wittmer, D., Luckenbill, B.K., Hill, H.H., Chen, Y.H.: ElectrosprayIonization Ion Mobility Spectrometry. Anal. Chem. 66, 2348-2355 (1994)

28. Clemmer, D.E., Hudgins, R.R., Jarrold, M.F.: Naked Protein Conformations: Cytochrome $c$ in the Gas Phase. J. Am. Chem. Soc. 117, 10141-10142 (1995)

29. von Helden, G., Wyttenbach, T., Bowers, M.T.: Conformation of Macromolecules in the Gas Phase: Use of Matrix-Assisted Laser Desorption Methods in Ion Chromatography. Science 267, 1483-1485 (1995)

30. von Helden, G., Wyttenbach, T., Bowers, M.T.: Inclusion of a MALDI Ion Source in the Ion Chromatography Technique: Conformational Information on Polymer and Biomolecular Ions. Int. J. Mass Spectrom. Ion Processes 146, 349-364 (1995)

31. Chen, Y.H., Siems, W.F., Hill Jr., H.H.: Fourier Transform Electrospray Ion Mobility Spectrometry. Anal. Chim. Acta 334(1/2), 75-84 (1996)

32. Gillig, K.J., Ruotolo, B., Stone, E.G., Russell, D.H., Fuhrer, K., Gonin, M., Schultz, A.J.: Coupling High-Pressure MALDI with Ion Mobility/Orthogonal Time-of-Flight Mass Spectrometry. Anal. Chem. 72, 3965-3971 (2000)

33. Hoaglund, C.S., Valentine, S.J., Sporleder, C.R., Reilly, J.P., Clemmer, D.E.: Three-Dimensional Ion Mobility/TOFMS Analysis of Electrosprayed Biomolecules. Anal. Chem. 70, 2236-2242 (1998)

34. Hoaglund-Hyzer, C.S., Li, J., Clemmer, D.E.: Mobility Labeling for Parallel CID of Ion Mixtures. Anal. Chem. 72, 2737-2740 (2000)

35. Bluhm, B.K., Gillig, K.J., Russell, D.H.: Development of a FourierTransform Ion Cyclotron Resonance Mass Spectrometer-Ion Mobility Spectrometer. Rev. Sci. Instrum. 71(11), 4078-4086 (2000)

36. Hoaglund-Hyzer, C.S., Clemmer, D.E.: Ion Trap/Ion Mobility/Quadrupole/Time-of-Flight Mass Spectrometry for Peptide Mixture Analysis. Anal. Chem. 73, 177-184 (2001)

37. Counterman, A.E., Clemmer, D.E.: Large Anhydrous Polyalanine Ions: Evidence for Extended Helices and Onset of a More Compact Structure. J. Am. Chem. Soc. 123, 1490-1498 (2001)

38. Tang, K., Shvartsburg, A.A., Lee, H.N., Prior, D.C., Buschbach, M.A., Li, F.M., Tolmachev, A.V., Anderson, G.A., Smith, R.D.: HighSensitivity Ion Mobility Spectrometry/Mass Spectrometry Using Electrodynamic Ion Funnel Interfaces. Anal. Chem. 77, 3330-3339 (2005)

39. Clowers, B.H., Siems, W.F., Hill, H.H., Massick, S.M.: Hadamard Transform Ion Mobility Spectrometry. Anal. Chem. 78(1), 44-51 (2006) 
40. Sun, W.J., May, J.C., Russell, D.H.: A Novel Surface-Induced Dissociation Instrument for Ion Mobility-Time-of-Flight Mass Spectrometry. Int. J. Mass Spectrom. 259(1/3), 79-86 (2007)

41. Baker, E.S., Tang, K.Q., Danielson III, W.F., Prior, D.C., Smith, R.D.: Simultaneous Fragmentation of Multiple Ions Using IMS Drift Time Dependent Collision Energies. J. Am. Soc. Mass Spectrom. 19(3), 411419 (2008)

42. Belov, M.E., Clowers, B.H., Prior, D.C., Danielson III, W.F., Liyu, A.V., Petritis, B.O., Smith, R.D.: Dynamically Multiplexed Ion Mobility Timeof-Flight Mass Spectrometry. Anal. Chem. 80(15), 5873-5883 (2008)

43. Valentine, S.J., Sevugarajan, S., Kurulugama, R.T., Koeniger, S.L., Merenbloom, S.I., Bohrer, B.C., Clemmer, D.E.J.: Proteome Res. 5, 1879-1887 (2006)
44. Kurulugama, R.T., Valentine, S.J., Sowell, R.A., Clemmer, D.E.: J. Proteomics 71(3), 318-331 (2008)

45. Kim, T., Tolmachev, A.V., Harkewicz, R., Prior, D.C., Anderson, G., Udseth, H.R., Smith, R.D., Bailey, T.H., Rakov, S., Futrell, J.H.: Design and Implementation of a New Electrodynamic Ion Funnel. Anal. Chem. 72, 2247-2255 (2000)

46. Shaffer, S.A., Tolmachev, A., Prior, D.C., Anderson, G.A., Udseth, H. R., Smith, R.D.: Characterization of an Improved Electrodynamic Ion Funnel Interface for Electrospray Ionization Mass Spectrometry. Anal. Chem. 71, 2957-2964 (1999)

47. Schwartz, J.C., Wade, A.P., Enke, C.G., Cooks, R.G.: Systematic Delineation of Scan Modes in Multidimensional Mass Spectrometry. Anal. Chem. 62, 1809-1818 (1990) 